\title{
The physiological roles of vesicular GABA transporter during embryonic development: a study using knockout mice
}

\author{
Kenzi Saito ${ }^{1,2}$, Toshikazu Kakizaki ${ }^{1,3}$, Ryotaro Hayashi ${ }^{4}$, Hiroshi Nishimaru ${ }^{5}$, Tomonori Furukawa ${ }^{6}$, Yoichi Nakazato ${ }^{7}$, \\ Shigeo Takamori ${ }^{8}$, Satoe Ebihara ${ }^{9}$, Masakazu Uematsu ${ }^{10}$, Masayoshi Mishina $^{11}$, Jun-ichi Miyazaki ${ }^{12}$, \\ Minesuke Yokoyama ${ }^{13}$, Shiro Konishi ${ }^{13}$, Koichi Inoue ${ }^{6}$, Atsuo Fukuda ${ }^{6}$, Manabu Fukumoto ${ }^{4}$, Kenji Nakamura ${ }^{13}$, \\ Kunihiko Obata ${ }^{14}$, Yuchio Yanagawa ${ }^{1,3^{*}}$
}

\begin{abstract}
Background: The vesicular GABA transporter (VGAT) loads GABA and glycine from the neuronal cytoplasm into synaptic vesicles. To address functional importance of VGAT during embryonic development, we generated global VGAT knockout mice and analyzed them.

Results: VGAT knockouts at embryonic day (E) 18.5 exhibited substantial increases in overall GABA and glycine, but not glutamate, contents in the forebrain. Electrophysiological recordings from E17.5-18.5 spinal cord motoneurons demonstrated that VGAT knockouts presented no spontaneous inhibitory postsynaptic currents mediated by GABA and glycine. Histological examination of E18.5 knockout fetuses revealed reductions in the trapezius muscle, hepatic congestion and little alveolar spaces in the lung, indicating that the development of skeletal muscle, liver and lung in these mice was severely affected.

Conclusion: VGAT is fundamental for the GABA- and/or glycine-mediated transmission that supports embryonic development. VGAT knockout mice will be useful for further investigating the roles of VGAT in normal physiology and pathophysiologic processes.
\end{abstract}

\section{Background}

GABAergic and glycinergic neurotransmissions play critical roles in the central nervous system (CNS), because they regulate network activity and are essential for a number of brain functions, such as cognition, perception, movement and respiration. In the adult mammalian CNS, GABA and glycine are the main inhibitory neurotransmitters, but in fetal life and early postnatal development, both neurotransmitters act as either excitatory or inhibitory, depending on the intracellular chloride concentration.

GABA is synthesized from glutamic acid by glutamate decarboxylase (GAD) [1] and is accumulated into synaptic vesicles by the vesicular GABA transporter

\footnotetext{
* Correspondence: yanagawa@med.gunma-u.ac.jp 'Department of Genetic and Behavioral Neuroscience, Gunma University Graduate School of Medicine, Maebashi 371-8511, Japan Full list of author information is available at the end of the article
}

(VGAT) [2,3]. Two isozymes of GAD, GAD65 and GAD67, are primarily expressed in GABAergic neurons [4,5]. GAD65 knockout mice exhibit spontaneous seizures, elevated anxiety and altered sensitivity to pain [6,7]. GAD67 knockout mice die of cleft palate at birth [8]. VGAT is present in both GABAergic and glycinergic neurons and is also called the vesicular inhibitory amino acid transporter (VIAAT) [3,9]. In addition to its presence at GABAergic and glycinergic synapses, the role of VGAT/VIAAT in GABA and glycine release is supported by electrophysiological evidence from primary cultured hippocampal or spinal cord neurons of VGAT knockout mice [10] and VGAT-transfected secretory cells [11]. VGAT knockout mice die perinatally and show a hunched posture, cleft palate and omphalocele [10].

Divergent roles for the VGAT proteins are implicated in the nervous system. However, the contribution of

\section{Biomed Central}


VGAT to tissues or cells outside of the CNS remains largely unclear. For example, neither muscle, lung nor liver phenotypes have been reported for these knockout mice. We independently generated VGAT knockout mice. To further investigate the roles of VGAT during development, we performed histopathological analyses in VGAT knockout muscle, lung and liver at an embryonic stage. These mice showed a reduction in the trapezius muscles, smaller saccules in the lung, and congestion in the liver. In addition, in VGAT knockout spinal cord motoneurons (MNs), spontaneous inhibitory postsynaptic currents (IPSCs) were absent. These experiments indicate that VGAT has an important role in the GABA - and/or glycine-mediated transmission that supports life. Preliminary results have been published in an abstract form [12].

\section{Results}

\section{Generation of $\mathrm{VGAT}^{-/-}$mice}

The targeting strategy used for the generation of VGAT knockout mice is shown in Figure 1A. Exons 2 and 3 encode the putative ten-transmembrane domain and $\mathrm{C}$ terminus of the VGAT protein [3,13], and accordingly, the deletion of these regions was expected to destroy the function of the VGAT protein. Correctly targeted ES cell clones isolated were microinjected into blastocysts to generate chimeric mice. These mice were then crossed with $\mathrm{C} 57 \mathrm{BL} / 6$ mice to generate heterozygous mice carrying one floxneo allele (VGAT ${ }^{\text {floxneo/+ }}$ mice).

We generated the VGAT knockout allele by crossing VGAT $^{\text {floxneo/+ }}$ mice with CAG-Cre mice, in which Cre recombinase is expressed ubiquitously [14]. Genotyping was performed by Southern blot analysis (Figure 1B) and PCR (Figure 1C), and the DNA sequences around the loxP site in the knockout allele were also confirmed (data not shown). To obtain homozygous VGAT knockout $\left(\mathrm{VGAT}^{-/-}\right)$mice, we intercrossed the $\mathrm{VGAT}^{+/-}$mice. Western blot analysis revealed no VGAT protein expression in embryonic day (E) 18.5 $\mathrm{VGAT}^{-/-}$brain, whereas VGAT protein expression in $\mathrm{VGAT}^{+/-}$mouse brains was reduced to about half of the wild-type level (Figure 1D). All E18.5 $\mathrm{VGAT}^{-/-}$fetuses displayed cleft palate (Figure 1E) and omphalocele (Figure 1F), phenotypes that are consistent with those described by Wojcik et al. [10].

No VGAT ${ }^{-/-}$mice survived beyond birth (Table 1 ). To estimate the time of death of $\mathrm{VGAT}^{-/-}$mice, we performed timed matings of the $\mathrm{VGAT}^{+/-}$mice and obtained the fetuses via cesarean section. Among the E18.5 offspring derived from the intercrosses of $\mathrm{VGAT}^{+/-}$mice, $\mathrm{VGAT}^{-/}$fetuses were obtained at the expected Mendelian ratio (27.3\%, $77 \mathrm{VGAT}^{-1-}$ of 282 littermates) and more than $97 \%$ of them (75 of 77) were alive (judged by their umbilical beats or heartbeats,
Table 1). When delivered by cesarean section on E18.5, both $\mathrm{VGAT}^{+/+}$(7 of 7) and $\mathrm{VGAT}^{+/-}$(11 of 12) fetuses began respiration, but none of the $\mathrm{VGAT}^{-1-}$ fetuses $(\mathrm{n}=$ 7) began to breathe. Therefore, it is probable that $\mathrm{VGAT}^{-/-}$mice died at birth due to respiratory failure.

\section{Elevations in GABA and glycine contents in $\mathrm{VGAT}^{-/-}$ forebrains}

In the absence of vesicular storage, neurotransmitter levels can be altered, and this alteration depends on the absence of the vesicular transporter. For example, monoamines are drastically reduced in vesicular monoamine transporter 2 knockout brains [15], but acetylcholine $(\mathrm{ACh})$ is increased in vesicular acetylcholine transporter (VAChT) knockout brains compared to control wild-type brains [16]. Therefore, we measured the amount of the neurotransmitters, GABA, glycine and glutamate in E18.5 $\mathrm{VGAT}^{-/-}$forebrain by HPLC. As shown in Figure 2A, $\mathrm{VGAT}^{-/}$fetuses showed significant increases in both GABA and glycine, but not glutamate, compared to $\mathrm{VGAT}^{+/+}$fetuses. It is possible that the increase in GABA content in $\mathrm{VGAT}^{-/-}$fetuses was due to the elevated expression levels of GABA-synthesizing enzymes. To test for this possibility, we analyzed the expression levels of GAD65 and GAD67 in the embryonic brains. Our Western blot analysis showed that the expression levels of both GAD65 and GAD67 in $\mathrm{VGAT}^{+/+}$and $\mathrm{VGAT}^{-/-}$brains were similar (Figure 2B). These results indicate that the increase in GABA content was not derived from elevated amounts of GABAsynthesizing enzymes in $\mathrm{VGAT}^{-/-}$embryos.

\section{Absence of functional inhibitory synaptic transmission in the $\mathrm{VGAT}^{-/-}$spinal cord}

To examine the physiological nature of synaptic inputs to spinal MNs, we performed whole-cell patch-clamp recordings using isolated spinal cord preparations taken from $\mathrm{VGAT}^{-/-}$and control mouse embryos. In these preparations, the neuronal connections within the spinal cord are kept relatively intact [17]. In control lumbar MNs, spontaneous outward currents were observed when the membrane potential was depolarized at $-40 \mathrm{mV}$ above the chloride ion reversal potential (approximately $-78 \mathrm{mV}$ in the present experimental condition). These currents were blocked by bath application of the glycinergic antagonist strychnine and the GABAergic antagonist picrotoxin, indicating that the currents were IPSCs $(n=8$, Figure 3A). In contrast, we did not detect such spontaneous IPSCs in $\mathrm{VGAT}^{-/-}$ MNs ( $n=12$, Figure $3 \mathrm{~B})$. When the membrane potential was held at $-70 \mathrm{mV}$, spontaneous inward currents were observed both in control and $\mathrm{VGAT}^{-/-}$MNs (Figure 3A and $3 \mathrm{~B})$. These inward currents were abolished by the concomitant bath application of the ionotropic 


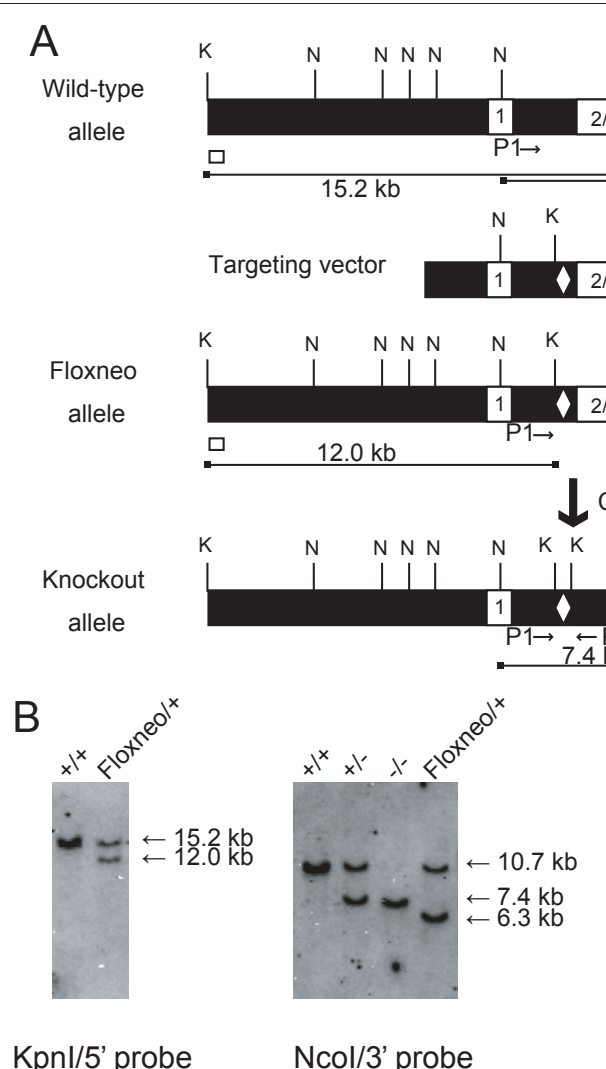

$\mathrm{Kpnl} / 5^{\prime}$ probe $\quad \mathrm{Ncol} / 3^{\prime}$ probe

E

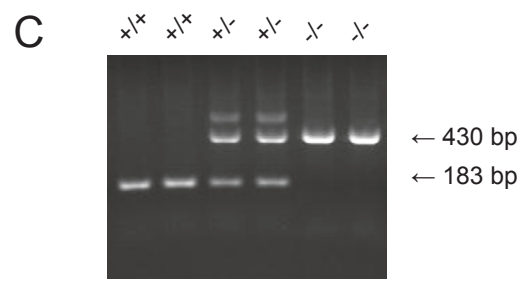

F

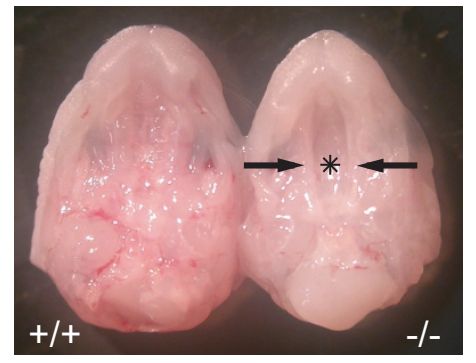

D
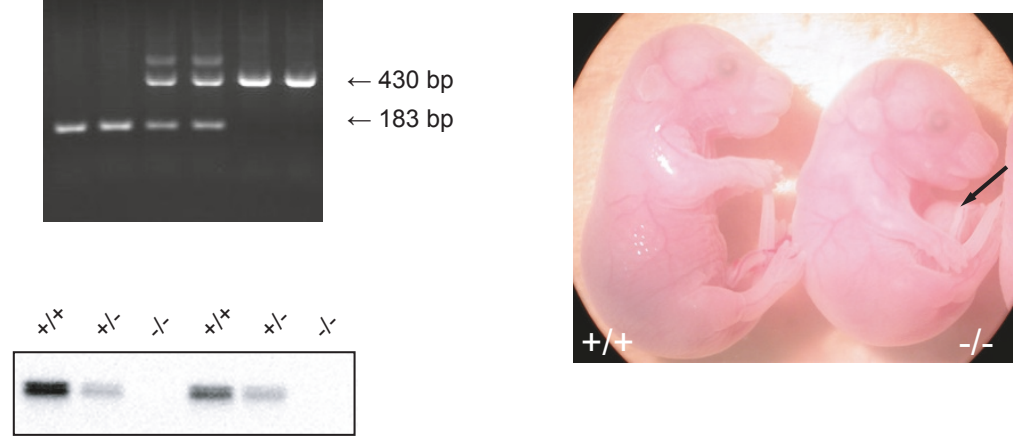

Figure 1 Generation of VGAT ${ }^{-1-}$ mice. (A) Schematic representation of the wild-type VGAT allele, the targeting vector, the VGAT-floxneo allele, and the VGAT knockout allele. Exons are represented by numbered white boxes. LoxP sites (open diamonds) and a PGK-Neo cassette (neo; gray box) flanked by the frt sites (open ellipses) were introduced into the wild-type VGAT locus by homologous recombination to produce the floxneo allele. The probes used for Southern blot analysis are indicated as white ( $5^{\prime}$ probe) and red (3' probe) boxes. The expected sizes of the Kpnl- and Ncol-digested genomic DNA fragments hybridized with the $5^{\prime}$ and $3^{\prime}$ probes, respectively, are indicated as lines under the schemes. Relevant restriction sites are indicated as follows: K, Kpnl; N, Ncol. PCR primers are indicated as arrows. (B) (Left) Southern blot analysis of Kpnldigested genomic DNA isolated from VGAT ${ }^{+/+}(+/+)$and VGATlloxneo/+ (Floxneo/+) mice using the $5^{\prime}$ probe indicated in A. The wild-type allele corresponds to the $15.2 \mathrm{~kb}$ band, whereas the floxneo allele corresponds to the $12.0 \mathrm{~kb}$ band. (Right) Southern blot analysis of Ncol-digested genomic DNA isolated from VGAT $T^{+/+}(+/+), V_{G A T}{ }^{/-}(+/-), V_{G A T} T^{/-}(-/)$, and VGAT floxneo/+ (Floxneo/+) mice using the $3^{\prime}$ probe indicated in A. The wild-type allele, the knockout allele, and the floxneo allele correspond to the $10.7 \mathrm{~kb}, 7.4 \mathrm{~kb}$, and $6.3 \mathrm{~kb}$ bands, respectively. (C) Genotyping of offspring from intercrosses of VGAT ${ }^{+-}$mice by PCR. Three primers were used (see Methods). Primers P2 and P3 produce a 183 bp fragment that represents the wild-type allele, whereas primers P1 and P3 produce a 430 bp fragment that represents the knockout allele. (D) Western blot analysis of E18.5 whole brain homogenates from VGAT ${ }^{+/+}(+/+), V_{G A T} T^{+-}(+/-), V_{G A T} T^{-}(-/-)$using the anti-VGAT antibody directed against an $\mathrm{N}$-terminal epitope. (E) Ventral views of the upper jaw of E18.5 VGAT ${ }^{1 /+}(+/+)$ and VGAT $T^{/-}(-/-)$mice. In contrast to the completely fused palate of a VGAT $T^{+/+}$mouse, secondary palatal shelves of a VGAT/- mouse did not contact each other (arrows), and its nasal cavity (asterisk) could be seen. (F) Lateral views of E18.5 VGAT ${ }^{+/+}(+/+)$and VGAT/- (-/-) mice. An arrow indicates omphalocele in a VGAT/- mouse. In addition, the VGAT/mouse showed an extremely hunched position in contrast to the $\mathrm{VGAT}^{+/+}$mouse. 
Table 1 Genotypes of offspring from intercrosses of VGAT ${ }^{+/-}$mice and phenotypes of VGAT ${ }^{/-}$mice $^{-1}$

\begin{tabular}{ccccccc}
\hline Age & \multicolumn{3}{c}{ Genotype } & \multicolumn{3}{c}{ Phenotype } \\
\cline { 2 - 7 } & $+/+$ & $+/-$ & $-/-$ & No. of -/- found dead & No. of -/- with omphalocele & No. of -/- with cleft palate \\
\hline E18.5 & 69 & 136 & 77 & $2 / 77^{*}$ & $77 / 77^{*}$ & $29 / 29^{*}$ \\
& $(24.5 \%)$ & $(48.2 \%)$ & $(27.3 \%)$ & & & Not determined \\
Newborn & 22 & 76 & 14 & $14 / 14^{*}$ & Not determined & \\
& $(19.6 \%)$ & $(67.9 \%)$ & $(12.5 \%)$ & & & \\
\hline
\end{tabular}

*affected/examined.

glutamate receptor blockers, a non-NMDA receptor antagonist 6-cyano-7-nitroquinoxaline-2,3-dione (CNQX) and an NMDA receptor antagonist D-2-amino5-phosphonovaleric acid (AP5), indicating that MNs received excitatory synaptic transmission in the $\mathrm{VGAT}^{-/-}$ spinal cord.

\section{Alterations in body weight, response to stimuli, trapezius muscle, liver and lung of $\mathrm{VGAT}^{-/-}$mice}

Wojcik et al. [10] reported that $\mathrm{VGAT}^{-1-}$ mice display the phenotypes such as cleft palate, omphalocele, hunched posture, immobility and stiffness. However, we proposed that there would be some other alterations in $\mathrm{VGAT}^{-/-}$ mice because VGAT is an essential molecule for GABAergic and glycinergic transmission. To address the question whether VGAT is essential for fetal growth, we initially measured the body weight of $\mathrm{VGAT}^{-1-}$ fetuses compared to $\mathrm{VGAT}^{+/+}$and $\mathrm{VGAT}^{+/-}$littermates. The body weight of the E18.5 $\mathrm{VGAT}^{-/-}$fetuses was significantly lower than that of $\mathrm{VGAT}^{+/+}$and $\mathrm{VGAT}^{+/-}$fetuses $\left(\mathrm{VGAT}^{+/+}: 1.18 \pm 0.11\right.$ grams, $\mathrm{n}=17 \mathrm{VGAT}^{+/-}: 1.20 \pm$ 0.08 grams, $\mathrm{n}=45$; $\mathrm{VGAT}^{-/-}: 1.05 \pm 0.11$ grams, $\mathrm{n}=32$ [mean $\pm \mathrm{SD}$ ], $\mathrm{P}<0.001$, one-way ANOVA, post hoc Fisher's least significant difference test). These results indicate that VGAT is important for fetal growth.

$\mathrm{VGAT}^{-/-}$fetuses exhibited immobility and lacked spontaneous limb and body movements, which are consistent with a report by Wojcik et al. [10]. To further address the question of whether the lack of movement in $\mathrm{VGAT}^{-/-}$ fetuses was restricted to a defect in spontaneous movement, we examined the response of E18.5 $\mathrm{VGAT}^{-1-}$ fetuses to mechanical stimuli. $\mathrm{VGAT}^{+/+}, \mathrm{VGAT}^{+/-}$and $\mathrm{VGAT}^{-/-}$fetuses were obtained via cesarean section and maintained alive in phosphate buffered saline. None of the $\mathrm{VGAT}^{-/-}$fetuses $(\mathrm{n}=16)$ responded to a pinch of the tail by forceps, but all VGAT ${ }^{+/+}(\mathrm{n}=16)$ and $\mathrm{VGAT}^{+/-}$ $(n=53)$ fetuses responded with a twisting of the trunk. These results suggest that $\mathrm{VGAT}^{-/-}$fetuses suffer from severe impairments in motor function.

Because the hunched posture observed in $\mathrm{VGAT}^{-/-}$ mice (Figure 1F) suggested defects in skeletal muscles or bones $[18,19]$, we performed a histological examination of skeletal muscles and bones in the E18.5 embryos. Trapezius muscle was thinner in $\mathrm{VGAT}^{-1-}$ mice than in the control mice (Figure 4A, B). The $\mathrm{VGAT}^{-/-}$ribs in the lower part were depressed, and their position was retracted toward the inside compared to control (Figure 4C, D). Furthermore, the spaces between each rib appeared narrower in $\mathrm{VGAT}^{-/-}$mice compared to the control mice (Figure 4C, D). Abdominal organs were examined histologically in an attempt to identify pathological findings associated with defects in $\mathrm{VGAT}^{-/-}$mice. Not only omphalocele (Figure $1 \mathrm{~F}$ ) but also hepatic congestion were characteristic of $\mathrm{VGAT}^{-/-}$embryos (Figure 4E, F). These results suggest that the crouching posture caused by an imbalance of the strength between the dorsal and ventral muscles made the thorax expand ineffectively, leading to an increase in intra-abdominal pressure in $\mathrm{VGAT}^{-1-}$ embryos. Although omphalocele can be caused by a malformation of the ventral body wall [20], the rectus abdominis muscle showed no apparent abnormality in $\mathrm{VGAT}^{-/-}$mice (data not shown).

The $\mathrm{VGAT}^{-/-}$mice lacked autonomous and jogglinginduced breathing movements, consistent with the report by Fujii et al. [21]. However, there is still uncertainty regarding the mechanism responsible for the respiratory failure caused by the loss of VGAT protein. To understand the pathology causing respiratory failure in $\mathrm{VGAT}^{-/-}$mice, we fixed embryos at E18.5, the day prior to birth, and performed pathohistology of the lungs. Examination under a microscope revealed that the $\mathrm{VGAT}^{-/-}$lung barely contained alveolar spaces compared to the control lung (Figure 4G, H). A possible cause of atelectasis was reported defect in the diaphragm [22]. We examined the $\mathrm{VGAT}^{-/-}$diaphragm histologically, but we didn't detect any difference in the diaphragm between the $\mathrm{VGAT}^{-/-}$and control mice.

The alterations in the $\mathrm{VGAT}^{-/-}$muscle, liver and lung were likely caused by the loss of VGAT in the CNS, but not the loss of VGAT in the peripheral tissue because VGAT transcripts were detected in brain and spinal cord, but not in muscle, liver or lung [2,3].

\section{Comparison of cleft palate and omphalocele between} $\mathrm{VGAT}^{-1-}$ mice and GAD67 $7^{-/-}$mice

Cleft palate is exhibited by $\mathrm{VGAT}^{-/-}$and $\mathrm{GAD}^{-/-}$mice $[8,10,23]$, demonstrating that GABAergic transmissions are involved in palatogenesis. Because VGAT and 


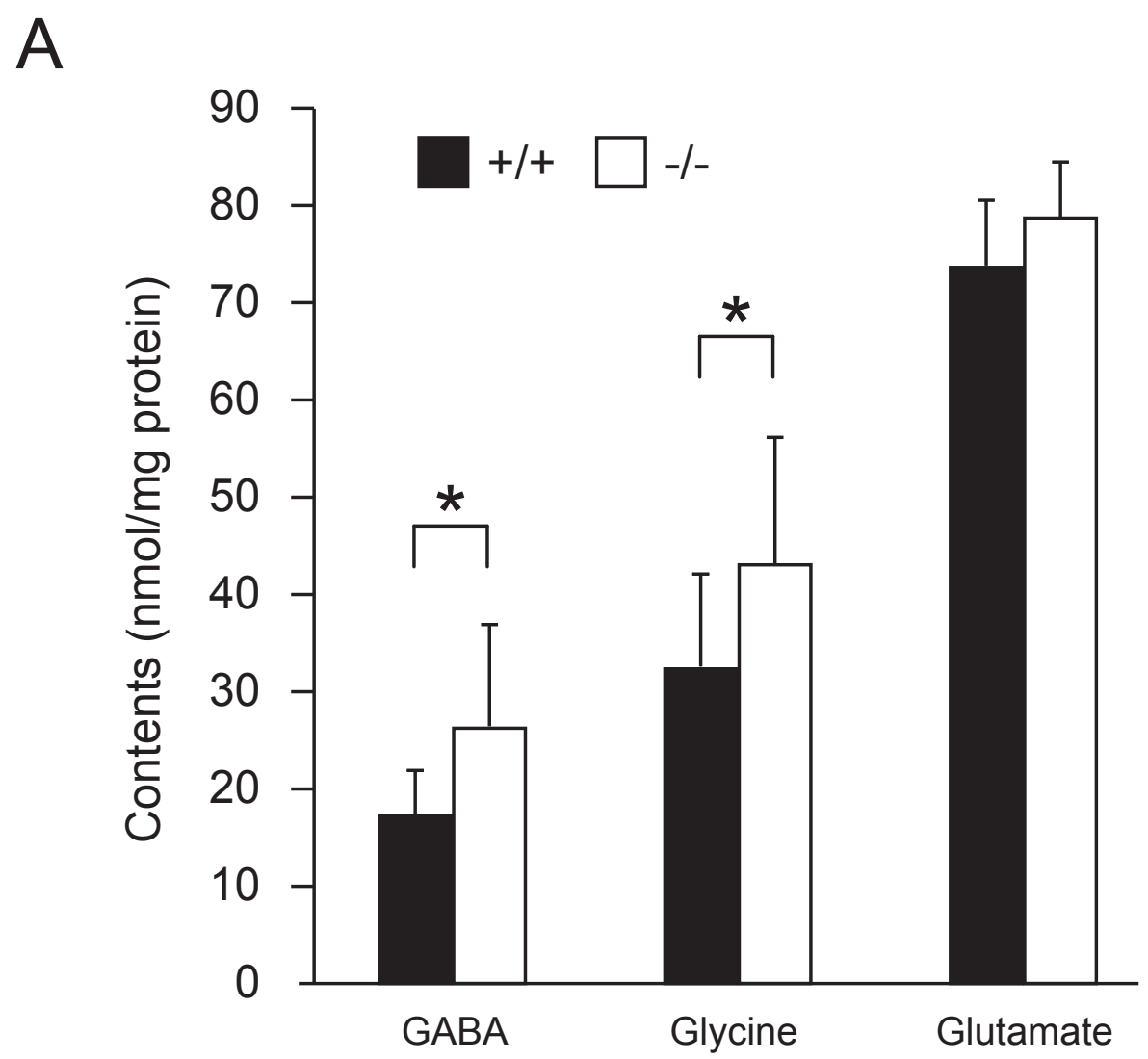

B

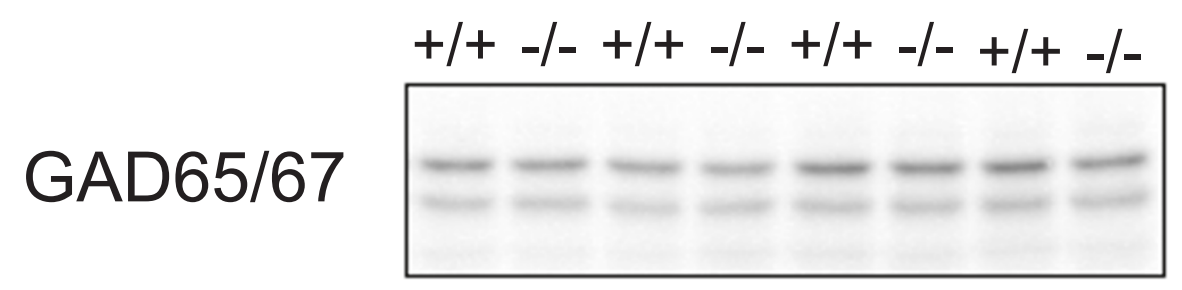

\section{$\beta$-actin}

Figure 2 Neurotransmitter contents and expression levels of GAD65 and GAD67. (A) Neurotransmitter contents of E18.5 mouse forebrain $\mathrm{VGAT}^{\prime-}$ mice showed significantly higher levels of GABA and glycine than VGAT ${ }^{+/+}$mice, but not glutamate. Values represent means \pm SD $\left({ }^{*} \mathrm{P}<\right.$ 0.05; Student's t-test, $\mathrm{n}=5-13$ per group). (B) Western blot analysis. The expression level of GAD65 and GAD67 in whole brain homogenates was not significantly different between $\mathrm{VGAT}^{+/+}(+/+)$and $\mathrm{VGAT}^{/-}(-/-)$mice. Equal amounts of protein were loaded and probed with an antibody that recognizes both GAD65 and GAD67. For the statistical comparison, the same blot was probed with anti- $\beta$-actin antibody as an internal control and measurements for GAD65 and GAD67 bands were normalized to the $\beta$-actin bands (GAD65: VGAT $T^{+/+} 100 \pm 23 \%$; VGAT/- $111 \pm 20 \%$, $\mathrm{n}=4, \mathrm{P}=0.71)\left(\mathrm{GAD67}: \mathrm{VGAT}^{+/+} 100 \pm 18 \% ; \mathrm{VGAT}^{\prime-} 93 \pm 17 \%, \mathrm{n}=4, \mathrm{P}=0.80\right)$. 


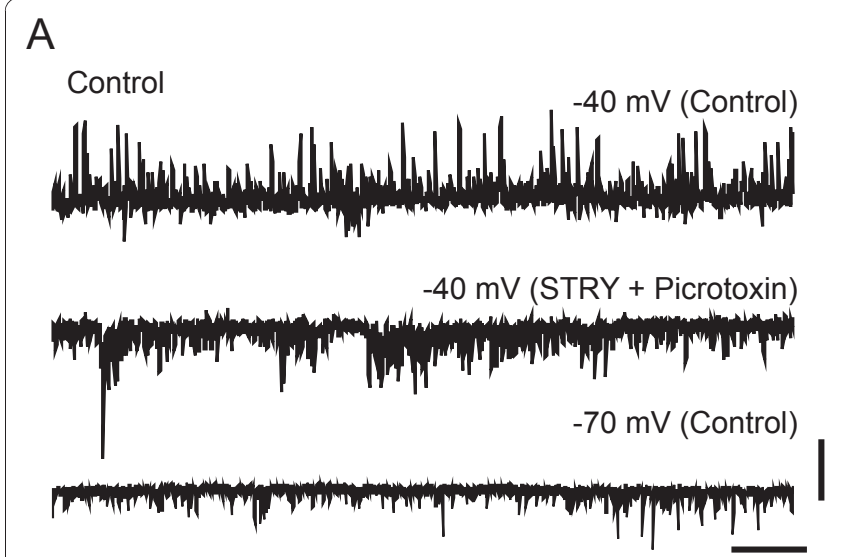

B

VGAT-/$-40 \mathrm{mV}$ (Control)

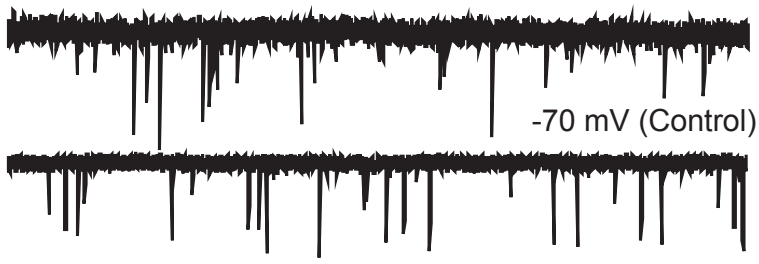

$-70 \mathrm{mV}(\mathrm{CNQX}+\mathrm{AP5})$

Figure 3 Electrophysiological characteristics of synaptic transmission in the VGAT ${ }^{-1-}$ spinal cord. (A) A representative whole-cell patchclamp recordings from control motoneurons (MNs) in a voltage clamp. In control motoneurons, spontaneous outward currents were observed when the membrane potential was held at $-40 \mathrm{mV}$ (upper trace). These currents were blocked by bath application of strychnine (STRY, $0.5 \mu \mathrm{M})$ and picrotoxin $(50 \mu \mathrm{M})$ (middle trace). Inward currents persisted in the presence of these antagonists and became prominent when the membrane potential was held at -70 mV. (B) In VGAT/- (VGAT-/-) MNs, no spontaneous outward currents were observed (upper trace). Inward

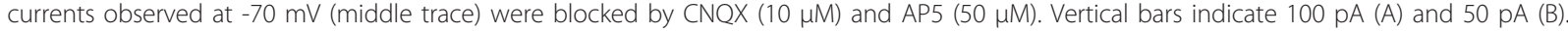

Horizontal bars indicate $2 \mathrm{~s}(\mathrm{~A}, \mathrm{~B})$.

GAD67 exhibit different molecular functions, we investigated whether the severity of cleft palate was different between $\mathrm{VGAT}^{-/-}$and GAD67 $7^{-1-}$ mice. Figure $5 \mathrm{~A}$ shows hematoxylin-eosin staining of coronal sections from the oral region. In the cleft palate of $\mathrm{VGAT}^{-/-}$mice, the palatal shelves remained vertical along the sides of the tongue (3 of 3). However, in GAD67 $7^{-1-}$ mice, the palatal shelves were elevated up to a horizontal position (3 of $3)$. In one of the GAD $67^{-/-}$mice, the palatal shelves even fused with each other completely (data not shown). These observations suggest that palatogenesis progresses further in $\mathrm{GAD}^{-1-}$ mice than in $\mathrm{VGAT}^{-/-}$mice. Our observations also suggest that cleft palate in $\mathrm{VGAT}^{-1-}$ mice is more severe than in GAD67 $7^{-/-}$mice.

The observation of omphalocele in $\mathrm{VGAT}^{-/-}$mice prompted us to investigate whether $\mathrm{GAD} 67^{-/-}$mice displayed omphalocele. We found omphalocele in GAD67 $7^{-1-}$ and $\mathrm{VGAT}^{-/-}$mice (Figure $5 \mathrm{~B}$ ), indicating that GABA signaling is involved in its onset. The incidence rate of omphalocele in GAD67 $7^{-/}$mice was 43\% (17 of 40), whereas the incidence in $\mathrm{VGAT}^{-/-}$mice was $100 \%$ (77 of 77; see also Table 1). Thus, the penetrance of omphalocele in $\mathrm{GAD}^{-1 /}$ mice was lower than in $\mathrm{VGAT}^{-/-}$mice. The size of omphalocele appeared to be larger in $\mathrm{VGAT}^{-/-}$mice than in GAD67/- mice. Taken together, these data suggest omphalocele in $\mathrm{GAD} 67^{-/-}$mice is less severe than in $\mathrm{VGAT}^{-1-}$ mice, similar to what was observed with the cleft palate.

\section{Discussion}

The present work addresses the contribution of VGAT to embryonic development. We generated VGAT mice and found that VGAT is fundamental for GABA and/or glycine release in the spinal cord. Moreover, in the absence of VGAT, there are profound effects on muscle, liver and lung during embryonic development. These observations bear important consequences for understanding the functional roles of VGAT from the cellular to the whole-body level.

\section{Generation of VGAT knockout mice}

Wojcik et al. [10] generated VGAT knockout mice, in which a mutation was inserted into exon 1 , and these mice exhibit cleft palate and omphalocele. Here, we generated floxed VGAT knockout mice, in which exons 2 and 3 of the VGAT gene were flanked by loxP sites. Crossing the floxed VGAT mice to CAG-Cre mice reproduced the phenotypes of cleft palate and omphalocele. Exons 1 and $2 / 3$ encode the cytoplasmic domain and the transmembrane domain, respectively $[3,13]$. Our results demonstrate that exons 2 and 3 are dispensable for the function of VGAT.

$\mathrm{VGAT}^{\text {floxneo/floxneo }}$ mice were born at the expected frequency, were viable, did not have a cleft palate or omphalocele, and were overtly indistinguishable from their wildtype littermates. Western blot showed that the level of VGAT protein expression in VGAT ${ }^{\text {floxneo/floxneo }}$ brain was not different from the wild-type brain (Additional file 1: Supplementary Figure S1). These results suggest that a loxP sequence and an frt-flanked phosphoglycerate kinase promoter-driven neomycin-resistance gene (PGK$\mathrm{Neo}$ ) inserted into intron 1 and the 3'-flanking region of the VGAT gene, respectively, do not affect the expression level of VGAT protein. Therefore, the VGAT-floxneo 


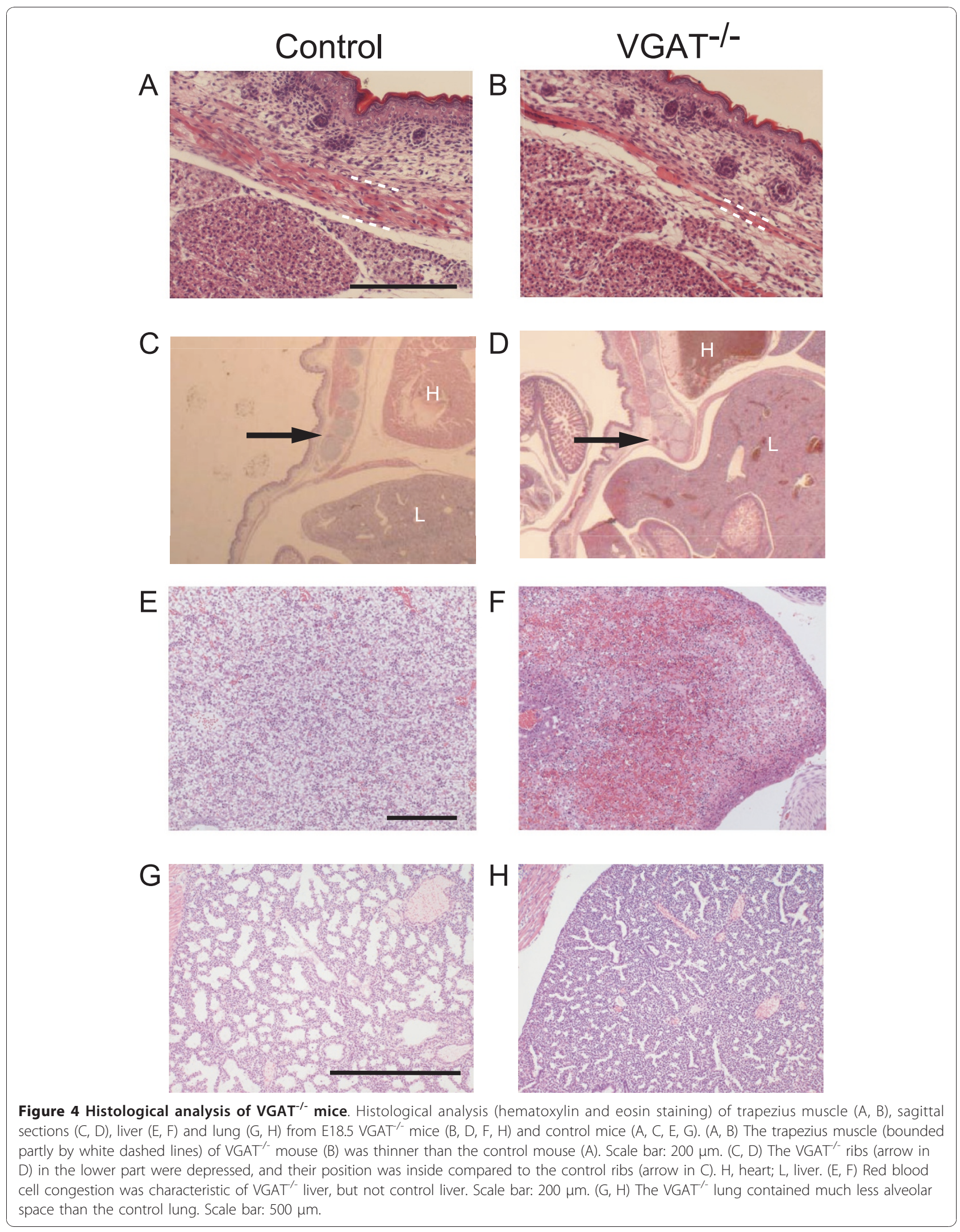




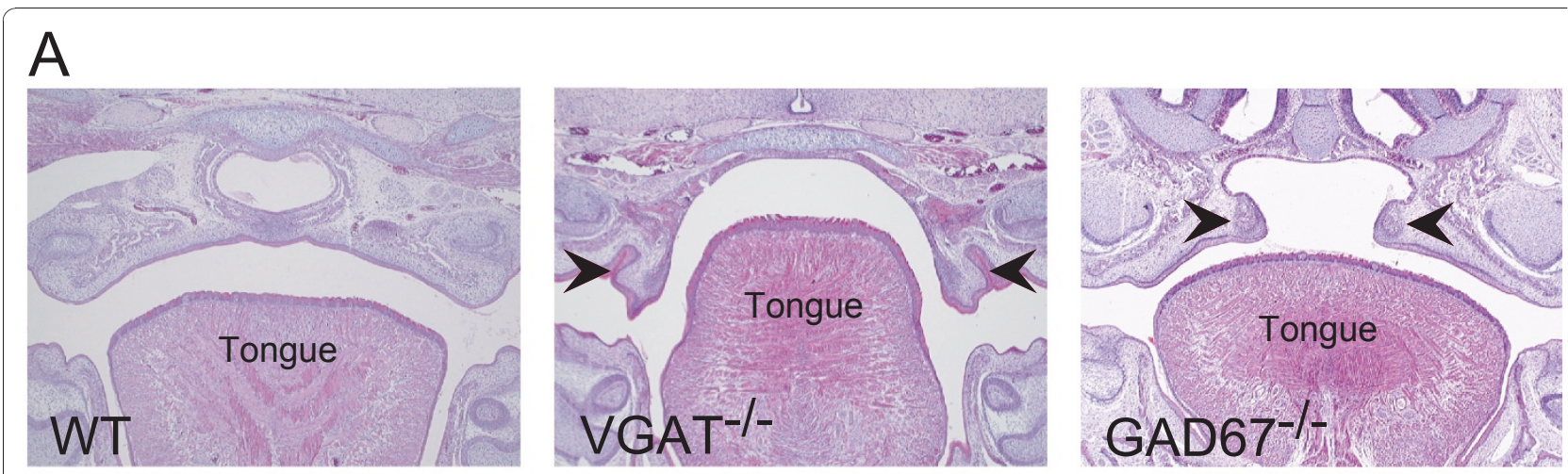

B

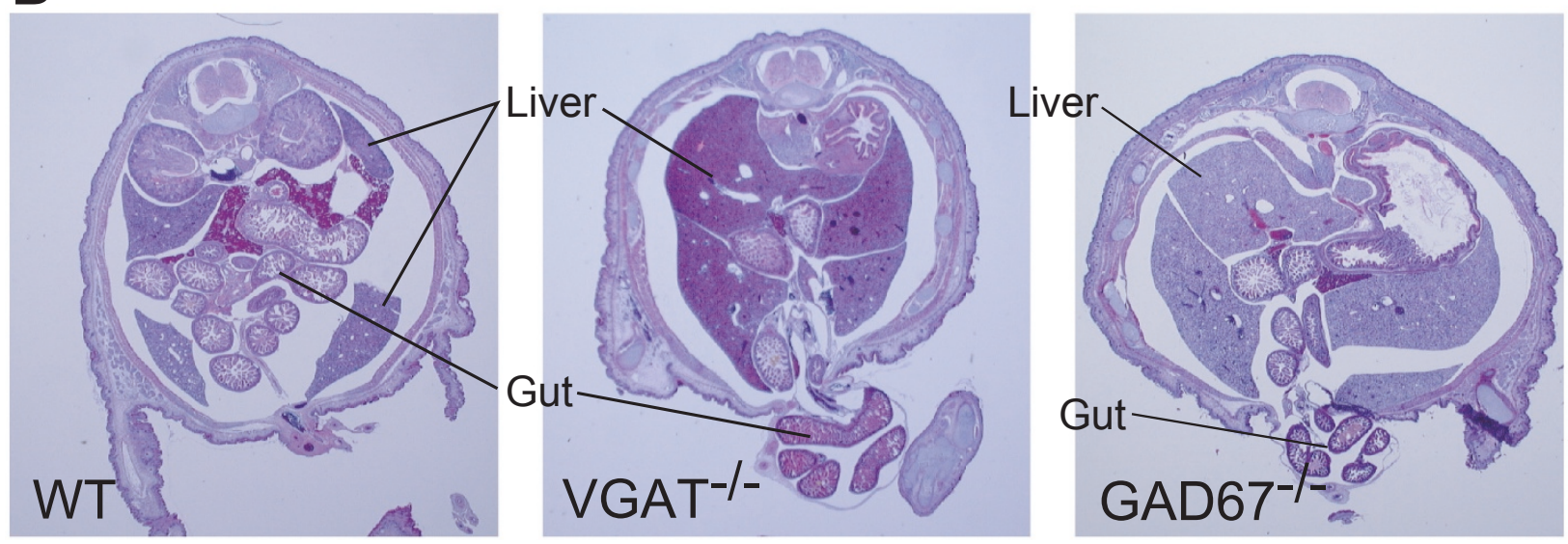

Figure 5 Histological comparison of omphalocele and cleft palate between VGAT ${ }^{-/}$and GAD67 ${ }^{-/-}$mice. (A) Hematoxylin-eosin stained coronal sections of the facial region of E18.5 wild-type (left panel), VGAT ${ }^{--}$(middle panel) and GAD67 ${ }^{-/}$(right panel) mice. Histological examination revealed that the secondary palatal shelves (arrowhead) of $\mathrm{VGAT}^{\prime-}$ mice were directed vertically down along the side of tongue in contrast to the fused palate of wild-type mice. In the cleft palate of $\mathrm{GAD} 67^{-1}$ mice (right panel), palatal shelves failed to fuse but were elevated horizontally unlike those in VGAT'- mice. (B) Hematoxylin-eosin stained coronal sections of the umbilical region of E18.5 wild-type (left panel), $\mathrm{VGAT}^{\prime-}$ (middle panel) and GAD67 $7^{- \text {- }}$ (right panel) embryos. The ventral body wall of the VGAT/- mice did not close and the gut protruded from the peritoneal cavity. In contrast to VGAT ${ }^{\prime-}$ mice, the ventral body wall of wild-type mice closed around the umbilicus, and the gut had already returned to the peritoneal cavity. The omphalocele in ${\mathrm{GAD} 67^{-1}}^{-}$mice was less severe than in $\mathrm{VGAT}^{1-}$ mice because a large amount of gut was

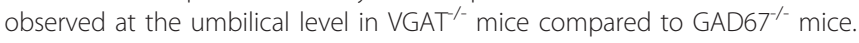

allele allowed for Cre-mediated conditional inactivation of the VGAT gene, and mice carrying these alleles will be useful in examining VGAT function at different developmental stages and in distinct cell types.

\section{Increase of overall GABA and glycine contents in $\mathrm{VGAT}^{-/-}$ forebrains}

We showed that both GABA and glycine contents were increased in the $\mathrm{VGAT}^{-/-}$forebrain, but not an excitatory neurotransmitter glutamate, which is transported into synaptic vesicles by vesicular glutamate transporters. An increase in GABA content in $\mathrm{VGAT}^{-/-}$mice is similar to that in ACh contents in VAChT knockout mice [16], but it is opposite of the decrease in monoamine contents in vesicular monoamine transporter 2 knockout mice. In C. elegans, the mutational inactivation of VGAT also leads to an increase in GABA immunoreactivity in GABAergic neurons [24]. In VAChT knockout mice the amount of the ACh-synthesizing enzyme choline acetyltransferase (ChAT) is increased at the mRNA and protein levels compared to their wildtype littermates, suggesting that the change in ChAT expression may be related to a compensatory mechanism due to the lack of ACh release [16]. Conversely, the amounts of the GABA-synthesizing enzymes GAD65 and GAD67 were not different in between the brains of $\mathrm{VGAT}^{-1-}$ mice and their control littermates (Figure 2B). Therefore, it is possible that the increased GABA in $\mathrm{VGAT}^{-1-}$ brain was due to a reduction in their degradation. GABA and glycine are released from presynaptic 
neurons into the synaptic cleft and are retrieved in neurons and glial cells by plasma membrane transporters $[25,26]$. GABA and glycine taken up in glial cells are further metabolized, but the GABA and glycine taken up in neurons are directly recycled into synaptic vesicles $[27,28]$. Because degradation systems for both GABA and glycine are mainly localized to glial cells [27,29], the transport into glial cells from the synaptic cleft is important for their degradation. Because the synaptic release of GABA and glycine was absent in $\mathrm{VGAT}^{-/-}$mice, the deletion of VGAT may result in little or no transport of GABA and glycine into glial cells. GABA and glycine then accumulate in the GABAergic and glycinergic neurons, respectively, but they are not degraded in the glial cells of $\mathrm{VGAT}^{-/-}$mice.

\section{Contribution of VGAT to motor function}

In the embryonic spinal cord of rodents, synaptic transmission to MNs mediated by GABA and glycine is prominent from the early fetal period [30,31]. Our results from the electrophysiological recordings of spinal cord MNs indicate that the inhibitory synaptic transmission was clearly absent in the VGAT knockout MNs, but that the excitatory synaptic transmission was present. Our results also suggest the absence of other functional mechanisms that transport GABA and/or glycine into synaptic vesicles in these synapses. $\mathrm{VGAT}^{-1-}$ fetuses at E17.5-18.5 not only were completely immobile and stiff, but also none of them responded to mechanical stimuli by pinching the limb or the tail. Therefore, it is probable that the lack of inhibitory transmission onto MNs in $\mathrm{VGAT}^{-/-}$fetuses resulted in defects in the spontaneous and stimulus-induced movements in vivo despite the presence of excitatory synaptic transmission.

In addition to the defect in motor movement, trapezius muscle displayed atrophy in $\mathrm{VGAT}^{-/-}$mice. Embryonic myogenesis progresses by the proliferation of myoblasts and fusion of myotubes, but it requires substantial cell death [32]. Physical forces play a significant role in the development and maintenance of skeletal muscle [33]. In cultured myoblasts, chronic and cyclic stretch results in an increase in cell death, including apoptosis [34]. Therefore, a possible explanation for the atrophy in $\mathrm{VGAT}^{-/-}$trapezius muscle is that stretching of the trapezius muscle due to the hunched posture caused an increase in apoptosis during development.

\section{Phenotypes of VGAT and GAD67 knockouts outside of the brain}

Ventral body wall closure abnormalities, such as omphalocele, are common human birth defects, but their molecular and cellular bases are poorly understood [35]. The mouse provides a model system to study the genetic defects and environmental insults that can lead to ventral body wall closure abnormalities [20]. In this study, omphalocele was observed in $\mathrm{VGAT}^{-1-}$ and GAD $67^{-1-}$ mice, indicating that the lack of GABA signaling was involved in its onset. Omphalocele has been observed in $\mathrm{K}^{+}-\mathrm{Cl}^{-}$-cotransporter 2 (KCC2) knockout mice [36], and $\mathrm{KCC} 2$ is required for GABA- and/or glycine-induced hyperpolarizing responses [37]. In the KCC2 knockout mice, GABA and/or glycine signals continue to act in an excitatory, but not an inhibitory, manner. Therefore, the omphaloceles observed in both $\mathrm{VGAT}^{-/-}$mice and GAD67 ${ }^{-/-}$mice resulted from defects in the inhibitory neurotransmission derived from the hyperpolarizing response. A lack of inhibitory transmission in $\mathrm{VGAT}^{-/-}$mice may lead to motor deficits, such as a hunched posture. It is likely that the hunched posture resulted in increases in both intrathoracic and intraabdominal pressures and this increased pressure caused omphalocele.

Concerning the mechanism of onset of cleft palate, studies using knockout mice have revealed associations between cleft palate and mutation of genes related to GABA signaling, such as GAD67 and GABRB3 [8,23,38]. Because the lack of the GAD67 gene leads to a reduction in tongue movement [39], the sluggish tongue may be an obstacle to development of the palatal shelves.

The cleft palate and omphalocele phenotypes were more severe in $\mathrm{VGAT}^{-/-}$mice than in $\mathrm{GAD}^{-/-}$mice. Glycinergic transmission is present in embryonic spinal cord and brainstem [40]. Hyperekplexia is a neurogenetic disorder caused mostly by mutations in the gene encoding the $\alpha 1$ subunit of glycine receptor and is characterized by an exaggerated startle response and neonatal hypertonia. In patients with hyperekplexia, the recurrent abdominal muscle contraction from the exaggerated startle response can increase the abdominal pressure and lead to omphalocele and inguinal hernia $[41,42]$. These reports suggest that a defect in glycinergic transmission is involved in the onset of omphalocele. A small amount of GABA is synthesized by another GAD isoform, GAD65, at the embryonic stage $[8,43]$. The differences in the severity between $\mathrm{VGAT}^{-/-}$and GAD $67^{-1-}$ mice must be due to the presence of both glycinergic and GAD65-produced GABAergic transmission in $\mathrm{GAD}^{-/-}$fetuses, but not in $\mathrm{VGAT}^{-/-}$fetuses.

\section{Conclusion}

In the present study, we established a VGAT knockout mouse, with which we demonstrated that VGAT is fundamental for GABAergic and/or glycinergic transmission. We also showed that VGAT is important for fetal growth and the development of muscle, liver and lung. The VGAT knockout mice described here may provide a useful tool for the study of specific functions of VGAT-dependent GABAergic and/or glycinergic 
transmission in mice. GABAergic neurons are classified into several subtypes according to the expression of chemical markers, such as parvalbumin and somatostatin $[44,45]$. Therefore, our floxed VGAT mice will be useful for conditional knockout studies to further investigate the role of VGAT in GABAergic neuronal subtypes.

\section{Methods}

\section{Animals}

All animal procedures were conducted in accordance with the guiding principles of the NIH under the review and approval of the Animal Care and Experimentation Committee, Gunma University, Showa Campus (Maebashi, Japan). Every effort was made to minimize the number of animals used and their suffering.

\section{Construction of the Targeting Vector}

Genomic BAC clones containing the mouse VGAT (mVGAT) locus were purchased, and the regions covering the entire VGAT gene were subcloned [13]. A genomic fragment spanning exons 1-3 of the mVGAT gene was used for the targeting vector (Figure 1; targeting vector). The HindIII (in the 5'-flanking region) - KpnI (in the 3'-flanking region) fragment $(7.5 \mathrm{~kb})$ was subcloned into pBluescript II KS(-), and the 5'-loxP site was introduced into the XbaI site (in intron 1). The 5'-loxP site was flanked by a KpnI site artificially introduced for Southern blot analysis. The $7.5 \mathrm{~kb}$ fragment was used as the 5 ' homologous region containing the 5'-flanking region, exons 1-3 and the 3'-flanking region. The frtflanked PGK-Neo cassette for positive selection of ES clones and the 3'-loxP site were inserted into the KpnI site (in the 3'-flanking region). The KpnI-BstEII fragment in the 3'-flanking region $(3.5 \mathrm{~kb})$ was added as the 3' homologous region. An MC1-DT-ApA cassette for negative selection [46] was ligated to the 3 ' end of the homologous region.

\section{Creation of a VGAT knockout allele}

The linearized targeting vector was introduced by electroporation into ES cells (CCE) of $129 / \mathrm{SvEv}$ mouse origin, and G418-resistant colonies were screened by Southern blot analysis using probes outside of the targeting vector. KpnI-digested genomic DNA prepared from ES cell colonies was hybridized with $5^{\prime}$ probes. The correctly targeted ES clones were injected into C57BL/6 blastocysts to produce germline chimeras. The germline chimeras were mated with C57BL/6 mice to establish the $\mathrm{VGAT}^{\text {floxneo/+ }}$ mouse line. VGAT ${ }^{\text {floxneo/+ }}$ mice were crossed with CAG-Cre mice [14] to excise exons 2 and 3 (VGAT knockout allele), and $\mathrm{VGAT}^{+/-}$ mice were obtained. We then intercrossed $\mathrm{VGAT}^{+/-}$ mice to generate $\mathrm{VGAT}^{-/-}$mice. When we performed timed matings of the $\mathrm{VGAT}^{+/-}$mice, the morning on the day of vaginal plug detection was designated E0.5.

Genotypes of $\mathrm{VGAT}^{+/+}, \mathrm{VGAT}^{+/-}$and $\mathrm{VGAT}^{-/-}$mice were determined by PCR using the following oligonucleotides: primer P1 (5'-AGTCTGATCCCGTGGCACTTCCAACTC-3') corresponding to intron 1 of the VGAT gene and primers P2 (5'-TCAGAGGCTTCT TCCTAGGGCTGCTG-3') and P3 (5'-GACCTCCCCCATTGCATAGAATGGCAC-3') corresponding to the 3'-flanking region of the VGAT gene. The primer set of P2 and P3 amplified a 183-bp fragment specific for the wild-type allele, and the primer set of P1 and P3 yielded a 430-bp fragment specific for the knockout allele.

\section{GAD67 knockout mice}

We used homozygous GAD67-GFP ( $\square$ neo) (GAD67 ${ }^{\text {GFP/ }}$ GFP) mice as GAD67 knockout (GAD67 ${ }^{-/-}$) mice. The generation of the GAD67-GFP ( $\square$ neo) mice and their genotyping by PCR were described previously $[47,48]$. In the GAD67-GFP ( $\square$ neo) mice, a cDNA encoding enhanced green fluorescent protein (EGFP) followed by an SV40 polyadenylation signal was targeted to the locus encoding GAD67 by homologous recombination, and the GAD67 gene was disrupted.

\section{Western blotting and measurement of neurotransmitter contents}

For Western blotting, homogenates prepared from E18.5 mouse brain were separated by $7.5 \%$ SDS-polyacrylamide gel electrophoresis, transferred to nitrocellulose membrane (Whatman, Maidstone, UK), and probed with antibodies specific for VGAT (1:1000) [49], GAD65/67 (1:1000) [50], synaptophysin (1:1000) (Synaptic Systems, Goettingen, Germany), and $\beta$-actin (1:10000) (Abcam, Cambridge, UK). After the membranes were washed with Tris- $\mathrm{HCl}$ buffered saline containing $0.05 \%(\mathrm{w} / \mathrm{v})$ Tween 20 , the bound antibodies were visualized with horseradish peroxidase-conjugated goat anti-mouse IgG or antirabbit IgG (Jackson ImmunoResearch Laboratories, West Grove, PA) using the ECL Western blotting detection system (GE Healthcare, London, UK). Protein levels were quantified using Light Capture and its quantification software (ATTO, Tokyo, Japan). Expression levels were normalized to $\beta$-actin or synaptophysin levels, and the values are expressed as means \pm SE. Statistical significance was assessed using Student's $t$-test.

GABA, glycine, and glutamate contents in the E18.5 mouse forebrain were measured according to previously described method [21,47].

\section{Electrophysiological recording in spinal cord}

Embryos (E17.5-18.5) of control $\left(\mathrm{VGAT}^{+/+} ; \mathrm{n}=3\right.$, $\left.\mathrm{VGAT}^{+/-} ; \mathrm{n}=5\right)$ and $\mathrm{VGAT}^{-/-}(\mathrm{n}=12)$ mice were 
decapitated and eviscerated, and the spinal cord was removed by ventral laminectomy. The isolated spinal cord was placed in a recording chamber perfused with oxygenated Ringer's solution (118.4 mM NaCl, $3 \mathrm{mM} \mathrm{KCl}, 2.52$ $\mathrm{mM} \mathrm{CaCl}_{2}, 1.25 \mathrm{mM} \mathrm{MgSO}_{4}, 25 \mathrm{mM} \mathrm{NaHCO}_{3}, 1.18 \mathrm{mM}$ $\mathrm{KH}_{2} \mathrm{PO}_{4}$, and $11.1 \mathrm{mM}$ D-glucose aerated with $5 \% \mathrm{CO}_{2}$ in $\mathrm{O}_{2}$ ) at room temperature. Recordings from MNs in the isolated spinal cord were performed as described previously [17]. Briefly, visually guided whole-cell tight-seal recording of MNs was performed with patch electrodes pulled from thick walled borosilicate glass to a final resistance of 5-8 M $\Omega$. The electrode tips were filled with (in $\mathrm{mM}) 138 \mathrm{~K}$-gluconate, $10 \mathrm{HEPES}, 1 \mathrm{CaCl}_{2}, 5 \mathrm{ATP}-\mathrm{Mg}$, and 0.3 GTP-Li. Intracellular signals were amplified with a Multiclamp 700B amplifier (Molecular Devices, Union City, CA), digitized at $5 \mathrm{kHz}$ with the Digidata 1440A data acquisition system (Molecular Devices) and saved on a hard disk for off-line analysis. Electrical stimulations of lumbar ventral roots (VRs) were performed using glass suction electrodes. MNs were identified visually as cells with large soma in the ventral horn and by observing the antidromic firing activated by the electrical stimulation of the adjacent VR. All drugs (CNQX, AP5, strychnine and picrotoxin; Sigma-Aldrich, St. Louis, MO) were dissolved in Ringer's solution and bath-applied to the preparation. Analysis was performed using pClamp 10 software (Molecular Devices).

\section{Histology}

$\mathrm{VGAT}^{-1-}, \mathrm{VGAT}^{+/-}$and $\mathrm{VGAT}^{+/+}$mice at E18.5 were investigated. Samples were fixed in $10 \%$ (vol/vol) formaldehyde, dehydrated with a graded series of ethanol solutions, and embedded in paraffin. Three-micrometer sections were prepared, subjected to paraffin removal by immersion in xylene, rehydrated, and stained with hematoxylin-eosin. $\mathrm{VGAT}^{+/-}$and $\mathrm{VGAT}^{+/+}$mice were mixed together and are referred to as control mice.

\section{Additional material}

Additional file 1: Supplementary Figure S1. VGAT expression levels in VGAT mutant mice. (A, B) VGAT expression level was normal in adult VGATfloxneo/floxneo mice. Western blot of whole brain homogenates from adult VGAT ${ }^{+/+}(+/+)$and VGAT floxneo/floxneo (floxneo/floxneo) mice is shown (A). VGAT expression level normalized to $\beta$-actin was not different between $V_{G A T^{+/+}}(+/+)$and VGAT floxneo/floxneo (floxneo/floxneo) mice (B). (C, D) VGAT expression level was reduced by about half in adult $V G A T^{+/-}$mice. Western blot of whole brain homogenates of adult VGAT $T^{+/}(+/+)$and VGAT ${ }^{+-}(+/-)$ mice is shown (C). VGAT expression level normalized to synaptophysin was significantly different between VGAT ${ }^{+/+}(+/+)$and $\mathrm{VGAT}^{+/}(+/-)$mice (D). Significance was tested by Student's t-test $\left({ }^{*} P<0.05\right)$.

\section{Acknowledgements}

The authors thank Ms. Honma, Ms. Hara and Ms. Yamazaki for technical assistance, and Ms. Shimoda and Ms. Owada for secretarial assistance. We thank Drs. Iso and Kurabayashi for the experiments and helpful discussion.
We also thank the staff at the Institute of Experimental Animal Research, Gunma University Graduate School of Medicine for technical help. This study was supported by Grants-in-Aid for Scientific Research from the Ministry of Education, Culture, Sports, Science and Technology (MEXT) of Japan, a grant from the Co-operative Study Program of National Institute for Physiological Sciences, Japan, Research for Promoting Technological Seeds, and Takeda Science Foundation.

\section{Author details}

${ }^{1}$ Department of Genetic and Behavioral Neuroscience, Gunma University Graduate School of Medicine, Maebashi 371-8511, Japan. ${ }^{2}$ The Graduate University for Advanced Studies, Hayama, Kanagawa 240-0193, Japan. ${ }^{3} J a p a n$ Science and Technology Agency, CREST, Tokyo 102-0075, Japan. ${ }^{4}$ Department of Pathology, Institute of Development, Aging and Cancer, Tohoku University, Sendai 980-8575, Japan. ${ }^{5}$ Graduate School of Comprehensive Human Science, University of Tsukuba, Tsukuba 305-8577, Japan. ${ }^{6}$ Department of Physiology, Hamamatsu University School of Medicine, Hamamatsu 431-3192, Japan. Department of Human Pathology, Gunma University Graduate School of Medicine, Maebashi 371-8511, Japan. ${ }^{8}$ Doshisha University Faculty of Life and Medical Sciences, Kyotanabe, Kyoto 610-0394, Japan. ${ }^{\circ}$ Department of Cellular Neurobiology, Graduate School of Medicine, University of Tokyo, Tokyo 113-0033, Japan. ${ }^{10}$ Department of Materials Science, Toyohashi University of Technology, Toyohashi 441-8580, Japan. ${ }^{11}$ Department of Molecular Neurobiology and Pharmacology, Graduate School of Medicine, University of Tokyo, Tokyo 113-0033, Japan. ${ }^{12}$ Division of Stem Cell Regulation Research, G6, Osaka University Graduate School of Medicine, 2-2 Yamadaoka, Suita, Osaka, 565-0871, Japan.

${ }^{13}$ Mitsubishi Kagaku Institute of Life Sciences, MITILS, 11 Minamiooya, Machida, Tokyo, 194-8511, Japan. ${ }^{14}$ Obata Research Unit, RIKEN Brain Science Institute, Wako 351-0198, Japan.

\section{Authors' contributions}

Conceived and designed the experiments: KS, TK, HN, YN, MY, SK, AF, MF, $\mathrm{KN}, \mathrm{KO}, \mathrm{YY}$. Performed the experiments: KS, TK, HN, TF, RH, ST, SE, MU, KI, MF, $K N, K O, Y Y$. Analyzed the data: KS, TK, HN, TF, RH, KI, AF, MF, KN, KO, YY. Contributed new reagents/analytical tools: ST, MM, JM. Wrote the paper: KS, TK, HN, AF, MF, KN, KO, YY. All authors read and approved the final manuscript.

\section{Competing interests}

The authors declare that they have no competing interests.

Received: 26 November 2010 Accepted: 30 December 2010 Published: 30 December 2010

\section{References}

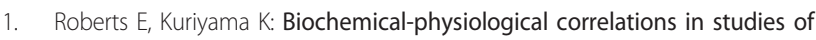
the gamma-aminobutyric acid system. Brain Res 1968, 8:1-35.

2. McIntire SL, Reimer RJ, Schuske K, Edwards RH, Jorgensen EM: Identification and characterization of the vesicular GABA transporter. Nature 1997, 389:870-876.

3. Sagne C, El Mestikawy S, Isambert MF, Hamon M, Henry JP, Giros B, Gasnier B: Cloning of a functional vesicular GABA and glycine transporter by screening of genome databases. FEBS Lett 1997, 417:177-183.

4. Bu DF, Erlander MG, Hitz BC, Tillakaratne NJ, Kaufman DL, WagnerMcPherson CB, Evans GA, Tobin AJ: Two human glutamate decarboxylases, 65-kDa GAD and 67-kDa GAD, are each encoded by a single gene. Proc Natl Acad Sci USA 1992, 89:2115-2119.

5. Esclapez M, Tillakaratne NJ, Kaufman DL, Tobin AJ, Houser CR: Comparative localization of two forms of glutamic acid decarboxylase and their mRNAs in rat brain supports the concept of functional differences between the forms. J Neurosci 1994, 14:1834-1855.

6. Stork O, Ji FY, Kaneko K, Stork S, Yoshinobu Y, Moriya T, Shibata S, Obata K: Postnatal development of a GABA deficit and disturbance of neural functions in mice lacking GAD65. Brain Res 2000, 865:45-58.

7. Kubo K, Nishikawa K, Ishizeki J, Hardy-Yamada M, Yanagawa Y, Saito S: Thermal hyperalgesia via supraspinal mechanisms in mice lacking glutamate decarboxylase 65. J Pharmacol Exp Ther 2009, 331:162-169.

8. Asada H, Kawamura Y, Maruyama K, Kume H, Ding RG, Kanbara N, Kuzume H, Sanbo M, Yagi T, Obata K: Cleft palate and decreased brain gamma-aminobutyric acid in mice lacking the 67-kDa isoform of glutamic acid decarboxylase. Proc Natl Acad Sci USA 1997, 94:6496-6499. 
9. Dumoulin A, Rostaing P, Bedet C, Lévi S, Isambert MF, Henry JP, Triller A, Gasnier B: Presence of the vesicular inhibitory amino acid transporter in GABAergic and glycinergic synaptic terminal boutons. J Cell Sci 1999, 112:811-823.

10. Wojcik SM, Katsurabayashi S, Guillemin I, Friauf E, Rosenmund C, Brose N, Rhee JS: A shared vesicular carrier allows synaptic corelease of GABA and glycine. Neuron 2006, 50:575-587.

11. Aubrey KR, Rossi FM, Ruivo R, Alboni S, Bellenchi GC, Le Goff A, Gasnier B, Supplisson S: The transporters GlyT2 and VIAAT cooperate to determine the vesicular glycinergic phenotype. J Neurosci 2007, 27:6273-6281.

12. Saito K, Nakamura K, Kakizaki T, Ebihara S, Uematsu M, Takamori S, Yokoyama M, Konishi S, Mishina M, Miyazaki Jl, Obata K, Yanagawa Y: Generation and analysis of vesicular GABA transporter knockout mouse [abstract]. Neurosci Res 2006, 55:S80.

13. Ebihara S, Obata K, Yanagawa Y: Mouse vesicular GABA transporter gene: genomic organization, transcriptional regulation and chromosomal localization. Brain Res Mol Brain Res 2003, 110:126-139.

14. Sakai K, Miyazaki J: A transgenic mouse line that retains Cre recombinase activity in mature oocytes irrespective of the cre transgene transmission. Biochem Biophys Res Commun 1997, 237:318-324.

15. Wang YM, Gainetdinov RR, Fumagalli F, Xu F, Jones SR, Bock CB, Miller GW, Wightman RM, Caron MG: Knockout of the vesicular monoamine transporter 2 gene results in neonatal death and supersensitivity to cocaine and amphetamine. Neuron 1997, 19:1285-1296.

16. de Castro BM, De Jaeger X, Martins-Silva C, Lima RD, Amaral E, Menezes C, Lima P, Neves CM, Pires RG, Gould TW, Welch I, Kushmerick C, Guatimosim C, Izquierdo I, Cammarota M, Rylett RJ, Gomez MV, Caron MG, Oppenheim RW, Prado MA, Prado VF: The vesicular acetylcholine transporter is required for neuromuscular development and function. Mol Cell Biol 2009, 29:5238-5250.

17. Nishimaru H, Restrepo CE, Ryge J, Yanagawa Y, Kiehn O: Mammalian motor neurons corelease glutamate and acetylcholine at central synapses. ProC Natl Acad Sci USA 2005, 102:5245-5249.

18. Toribio RE, Brown HA, Novince CM, Marlow B, Hernon K, Lanigan LG, Hildreth BE, Werbeck JL, Shu ST, Lorch G, Carlton M, Foley J, Boyaka P, McCauley LK, Rosol TJ: The midregion, nuclear localization sequence, and C terminus of PTHrP regulate skeletal development, hematopoiesis, and survival in mice. FASEB J 2010, 24:1947-1957.

19. Yoda E, Hachisu K, Taketomi Y, Yoshida K, Nakamura M, Ikeda K, Taguchi R, Nakatani Y, Kuwata H, Murakami M, Kudo I, Hara S: Mitochondrial dysfunction and reduced prostaglandin synthesis in skeletal muscle of Group VIB Ca2+-independent phospholipase A2gamma-deficient mice. J Lipid Res 2010, 51:3003-3015.

20. Brewer S, Williams T: Finally, a sense of closure? Animal models of human ventral body wall defects. Bioessays 2004, 26:1307-1321.

21. Fujii M, Arata A, Kanbara-Kume N, Saito K, Yanagawa Y, Obata K: Respiratory activity in brainstem of fetal mice lacking glutamate decarboxylase 65/67 and vesicular GABA transporter. Neuroscience 2007, 146:1044-1052.

22. Baertschi S, Zhuang L, Trueb B: Mice with a targeted disruption of the Fgfrl1 gene die at birth due to alterations in the diaphragm. FEBS J 2007, 274:6241-6253.

23. Condie BG, Bain G, Gottlieb DI, Capecchi MR: Cleft palate in mice with a targeted mutation in the gamma-aminobutyric acid-producing enzyme glutamic acid decarboxylase 67. Proc Natl Acad Sci USA 1997, 94:11451-11455.

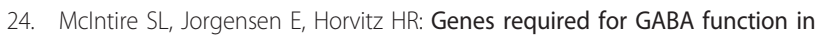
Caenorhabditis elegans. Nature 1993, 364:334-337.

25. Aragon C, Lopez-Corcuera B: Structure, function and regulation of glycine neurotransporters. Eur J Pharmacol 2003, 479:249-262.

26. Conti F, Minelli A, Melone M: GABA transporters in the mammalian cerebral cortex: localization, development and pathological implications. Brain Res Brain Res Rev 2004, 45:196-212.

27. Cherubini E, Conti F: Generating diversity at GABAergic synapses. Trends Neurosci 2001, 24:155-162.

28. Schousboe A: Role of astrocytes in the maintenance and modulation of glutamatergic and GABAergic neurotransmission. Neurochem Res 2003, 28:347-352.

29. Sato K, Yoshida S, Fujiwara K, Tada K, Tohyama M: Glycine cleavage system in astrocytes. Brain Res 1991, 567:64-70.
30. Nishimaru H, lizuka M, Ozaki S, Kudo N: Spontaneous motoneuronal activity mediated by glycine and GABA in the spinal cord of rat fetuses in vitro. J Physiol 1996, 497:131-143.

31. Hanson MG, Landmesser LT: Characterization of the circuits that generate spontaneous episodes of activity in the early embryonic mouse spinal cord. J Neurosci 2003, 23:587-600

32. Sandri M, Carraro U: Apoptosis of skeletal muscles during development and disease. Int J Biochem Cell Biol 1999, 31:1373-1390.

33. Proske U, Morgan DL: Muscle damage from eccentric exercise: mechanism, mechanical signs, adaptation and clinical applications. J Physiol 2001, 537:333-345.

34. Liu J, Liu J, Mao J, Yuan X, Lin Z, Li Y: Caspase-3-mediated cyclic stretchinduced myoblast apoptosis via a Fas/FasL-independent signaling pathway during myogenesis. J Cell Biochem 2009, 107:834-844.

35. Williams T: Animal models of ventral body wall closure defects: a personal perspective on gastroschisis. Am J Med Genet C Semin Med Genet 2008, 148C:186-191.

36. Hubner CA, Stein V, Hermans-Borgmeyer I, Meyer T, Ballanyi $K$, Jentsch TJ: Disruption of $\mathrm{KCC} 2$ reveals an essential role of $\mathrm{K}-\mathrm{Cl}$ cotransport already in early synaptic inhibition. Neuron 2001, 30:515-524.

37. Delpire E: Cation-Chloride Cotransporters in Neuronal Communication. News Physiol Sci 2000, 15:309-312.

38. Homanics GE, DeLorey TM, Firestone LL, Quinlan JJ, Handforth A, Harrison NL, Krasowski MD, Rick CE, Korpi ER, Makela R, Brilliant MH, Hagiwara N, Ferguson C, Snyder K, Olsen RW: Mice devoid of gammaaminobutyrate type A receptor beta3 subunit have epilepsy, cleft palate, and hypersensitive behavior. Proc Natl Acad Sci USA 1997, 94:4143-4148.

39. Tsunekawa N, Arata A, Obata K: Development of spontaneous mouth/ tongue movement and related neural activity, and their repression in fetal mice lacking glutamate decarboxylase 67. Eur J Neurosci 2005, 21:173-178.

40. Greer JJ, Funk GD: Perinatal development of respiratory motoneurons. Respir Physiol Neurobiol 2005, 149:43-61.

41. Suhren O, Bruyn GW, Tuynman JA: Hyperexplexia - A Hereditary Startle Syndrome. J Neurol Sci 1966, 3:577-605.

42. Zhou L, Chillag KL, Nigro MA: Hyperekplexia: a treatable neurogenetic disease. Brain Dev 2002, 24:669-674.

43. Ji F, Kanbara N, Obata K: GABA and histogenesis in fetal and neonatal mouse brain lacking both the isoforms of glutamic acid decarboxylase. Neurosci Res 1999, 33:187-194.

44. Kawaguchi Y, Kondo S: Parvalbumin, somatostatin and cholecystokinin as chemical markers for specific GABAergic interneuron types in the rat frontal cortex. J Neurocytol 2002, 31:277-287.

45. Ascoli GA, Alonso-Nanclares L, Anderson SA, Barrionuevo G, BenavidesPiccione R, Burkhalter A, Buzsáki G, Cauli B, Defelipe J, Fairén A, Feldmeyer D, Fishell G, Fregnac Y, Freund TF, Gardner D, Gardner EP, Goldberg JH, Helmstaedter M, Hestrin S, Karube F, Kisvárday ZF, Lambolez B, Lewis DA, Marin O, Markram H, Muñoz A, Packer A Petersen CC, Rockland KS, Rossier J, Rudy B, Somogyi P, Staiger JF, Tamas G, Thomson AM, Toledo-Rodriguez M, Wang Y, West DC, Yuste R: Petilla terminology: nomenclature of features of GABAergic interneurons of the cerebral cortex. Nat Rev Neurosci 2008, 9:557-568.

46. Yanagawa Y, Kobayashi T, Ohnishi M, Kobayashi T, Tamura S, Tsuzuki T, Sanbo M, Yagi T, Tashiro F, Miyazaki J: Enrichment and efficient screening of ES cells containing a targeted mutation: the use of DT-A gene with the polyadenylation signal as a negative selection maker. Transgenic Res 1999, 8:215-221.

47. Tamamaki N, Yanagawa Y, Tomioka R, Miyazaki J, Obata K, Kaneko T: Green fluorescent protein expression and colocalization with calretinin, parvalbumin, and somatostatin in the GAD67-GFP knock-in mouse. $J$ Comp Neurol 2003, 467:60-79.

48. Kaneko K, Tamamaki N, Owada H, Kakizaki T, Kume N, Totsuka M, Yamamoto T, Yawo H, Yagi T, Obata K, Yanagawa Y: Noradrenergic excitation of a subpopulation of GABAergic cells in the basolateral amygdala via both activation of nonselective cationic conductance and suppression of resting $\mathrm{K}+$ conductance: a study using glutamate decarboxylase 67-green fluorescent protein knock-in mice. Neuroscience 2008, 157:781-797.

49. Takamori S, Riedel D, Jahn R: Immunoisolation of GABA-specific synaptic vesicles defines a functionally distinct subset of synaptic vesicles. $J$ Neurosci 2000, 20:4904-4911. 
50. Asada H, Kawamura Y, Maruyama K, Kume H, Ding R, Ji FY, Kanbara N, Kuzume H, Sanbo M, Yagi T, Obata K: Mice lacking the $65 \mathrm{kDa}$ isoform of glutamic acid decarboxylase (GAD65) maintain normal levels of GAD67 and GABA in their brains but are susceptible to seizures. Biochem Biophys Res Commun 1996, 229:891-895.

doi:10.1186/1756-6606-3-40

Cite this article as: Saito et al:: The physiological roles of vesicular GABA transporter during embryonic development: a study using knockout mice. Molecular Brain 2010 3:40.

Submit your next manuscript to BioMed Central and take full advantage of:

- Convenient online submission

- Thorough peer review

- No space constraints or color figure charges

- Immediate publication on acceptance

- Inclusion in PubMed, CAS, Scopus and Google Scholar

- Research which is freely available for redistribution

Submit your manuscript at www.biomedcentral.com/submit
() Biomed Central 